OPEN ACCESS

Edited by:

MoezAllslam Ezzat Faris, University of Sharjah, United

Arab Emirates

Reviewed by:

Falak Zeb,

National University of Medical

Sciences (NUMS), Pakistan

Agnieszka Micek,

Jagiellonian University, Poland

Nivine Hanach,

Maastricht University, Netherlands

*Correspondence:

Wenbin $\mathrm{Li}$

liwenbin@ccmu.edu.cn

Specialty section

This article was submitted to

Nutritional Epidemiology,

a section of the journal

Frontiers in Nutrition

Received: 13 December 2021

Accepted: 13 January 2022

Published: 14 February 2022

Citation:

Zhang W, Jiang J, Li X, He Y, Chen F and Li W (2022) Dietary Factors and Risk of Glioma in Adults: A Systematic

Review and Dose-Response Meta-Analysis of Observational Studies. Front. Nutr. 9:834258. doi: 10.3389/fnut.2022.834258

\section{Dietary Factors and Risk of Glioma in Adults: A Systematic Review and Dose-Response Meta-Analysis of Observational Studies}

\author{
Weichunbai Zhang ${ }^{1}$, Jing Jiang ${ }^{1}$, Xinyi $\mathrm{Li}^{2}$, Yongqi He ${ }^{1}$, Feng Chen ${ }^{1}$ and Wenbin $\mathrm{Li}^{1 *}$ \\ ${ }^{1}$ Department of Neuro-Oncology, Cancer Center, Beijing Tiantan Hospital, Capital Medical University, Beijing, China, ${ }^{2}$ College \\ of Nursing, University of South Florida, Tampa, FL, United States
}

Background: Gliomas are the most common primary intracranial tumors in adults. Inappropriate dietary habits are thought to be a risk factor for most human cancer, and glioma is no exception. However, the effect of dietary factors on glioma is not clear.

Objective: This review aims to quantitatively evaluate the association between various dietary intakes and glioma using a meta-analysis.

Methods: We searched articles on PubMed, the Cochrane Library, the Web of Science, and EMBASE from their inception until October 11, 2021. According to heterogeneity, the fixed-effects or random-effects model was selected to obtain the relative risk (RR) of merger. Based on the methods described by Greenland and Longnecker, we explored the dose-response relationship between dietary intakes and the risk of glioma. Subgroup analysis, sensitivity analysis, and publication bias were also used.

Results: This study reviewed 33 articles, including 3,606,015 controls and 8,831 patients with glioma. This study included 12 food groups. Compared with the lowest intakes, the highest intakes of tea $(R R=0.82,95 \% \mathrm{Cl}: 0.71-0.93)$, total vegetables $(R R=$ $0.84,95 \% \mathrm{Cl}: 0.70-1.00)$, green vegetables ( $R R=0.80,95 \% \mathrm{Cl}: 0.66-0.98)$, and orange vegetables $(R R=0.79,95 \% \mathrm{Cl}: 0.66-0.96)$ significantly reduced the risk of glioma, while the highest intakes of grains ( $R R=1.39,95 \% \mathrm{Cl}: 1.16-1.66)$, processed meats $(R R=$ 1.19, 95\%Cl: $1.00-1.42)$, and processed fish ( $R R=1.37,95 \% \mathrm{Cl}: 1.03-1.84)$ significantly increased the risk of glioma. The results of subgroup and sensitivity analyses remained unchanged. In the dose-response relationship, only tea was statistically significant. Taking an extra cup of tea every day reduced the risk of glioma by $4 \%$.

Conclusions: Our analysis suggests that the intakes of tea, total vegetables, green vegetables, and orange vegetables may reduce the risk of glioma, while the intakes of grains, processed meats, and processed fish may increase the risk of glioma. Therefore, the effect of dietary factors on glioma should not be ignored.

\section{Systematic Review Registration: https://www.crd.york.ac.uk/prospero/, CRD42022296658.}

Keywords: glioma, meta-analysis, dose-response relationship, observational study, dietary factors 


\section{INTRODUCTION}

Gliomas are the most prevalent types of adult brain tumors, accounting for $78 \%$ of malignant brain tumors (1). Because of its low morbidity, high mortality, rapid onset, and easy recurrence, it has caused a serious disease burden for people. Due to the aggressive nature of gliomas, a complete surgical resection is difficult to achieve (2). The prevention of glioma has become one of the important anti-disease strategies. Therefore, the etiology of glioma has become a major focus in the past three decades. Several studies have focused on endogenous factors such as allergic diseases (3), genetic susceptibility, head injury (4), and multiple alleles that have been found to be associated with glioma risk, while frequent exposures to ionizing radiation have been found to significantly increase glioma risk among environmental risk factors (5).

Inappropriate dietary habits such as long-term consumption of processed meats (grilled, smoked, cured red, and white meats) and insufficient intakes of vegetables and fruits are thought to be a risk factor for most human cancer, and glioma is no exception (6). Currently, a few studies that investigate dietaryassisted glioma therapy have found mostly positive effects $(7,8)$. However, the results of nutritional epidemiological studies on the etiology of glioma are not satisfactory. Although a few studies have been reported on the effect of daily dietary factors, including vegetables, fruits, meats, fish, and non-alcoholic beverages, the evidence remained difficult to reconcile. Terry et al. (9) found a protective effect of higher intakes of vegetables against glioma in a multicenter case-control study [odds ratio $(\mathrm{OR})=0.7$, 95\%CI: 0.5-0.9]. And, both green and orange vegetables had independent protective effects. Chen et al. also found that the intakes of vitamin $\mathrm{A}$ and carotene-rich in vegetables were significantly negatively correlated with glioma in the case-control study (vitamin A: OR $=0.5, P_{\text {-trend }}=0.005 ; \alpha$-carotene: $\mathrm{OR}=$ $0.5, P_{\text {-trend }}=0.01, \beta$-carotene: $\left.\mathrm{OR}=0.5, P_{\text {-trend }}=0.01\right)(10)$. Blowers et al. found that nitroso-exposed diets such as processed meats increase the risk of glioma, especially bacon ( $\mathrm{OR}=6.6$, 95\%CI: 1.9-22.5), but taking vitamin supplements seems to have a protective effect (11). None of the observational studies on fish intakes and glioma found significant results (10-12), but a meta-analysis showed that dietary intakes of fresh fish reduced the risk of glioma [relative risk $(\mathrm{RR})=0.823$, 95\%CI: 0.70-0.97] (13). A population cohort study with an average follow-up of 14.1 years found no evidence that various types of meats (red meats, processed meats, or subtypes of meats) or iron (total or heme) was associated with glioma (14). Similar results were found for the other processed meats $(15,16)$. The impact of tea and coffee on glioma has also attracted much attention. Two prospective studies have shown that tea has a protective effect against glioma. Every extra cup of tea daily could reduce the risk of glioma by $7 \%$, while the result of coffee was not significant $(17,18)$. Pranata et al. obtained the same conclusion through a meta-analysis (19). However, in three large prospective cohort studies in the UK and the USA, Kuan et al. analyzed the effects of 15 food groups on glioma at different follow-up times, no significant effect was found (20). Finally, the incidence rate of gliomas is significantly lower compared with other cancers. Thus, only a relatively small number of cases can be obtained even with large cohort studies. This may be the main reason for the inconsistent research results.

To provide a quantitative assessment of the effect of dietary intakes on glioma risk, we synthesized all published observational studies on dietary factors and glioma. We used the dose-response meta-analysis to quantify this association between dietary factors and glioma risk and to determine whether the relationship is linear, targeting to reach some evidence for dietary factors to prevent glioma.

\section{METHODS}

\section{Search Strategy}

Two authors independently conducted an extensive search of the Cochrane Library, PubMed, Web of Science, and Embase until October 11, 2021. The Cochrane Library search terms used for the title, abstract, and keywords were "glioma" OR "brain cancer" OR "brain tumor" combined with "diet" OR "food" OR "lifestyle" OR "nutrition" OR "fruit" OR "vegetable" OR “meat” OR “coffee” OR "tea” OR "fish" OR "vitamin.” The same retrieval strategy was also applied to the other databases. No document type, language, or other relevant restrictions were used in the retrieval process, and the unpublished articles were excluded. Two reviewers screened the titles and abstracts to select the articles and reviewed the full text. Any disagreements between the two authors were settled by a third author. In addition, we searched the references of the published meta-analysis to identify other potential articles.

\section{Inclusion and Exclusion Criteria}

For the meta-analysis, we included the articles that met the following criteria: (1) Exposure: the dietary intakes of participants. The exposure of interest was dietary intakes of participants. The studies gave the daily intakes of each food or the overall intakes of a food group through food frequency questionnaires or dietary recall; (2) Outcome: glioma; and (3) Population: 18 years old and above. This was due to the large dietary differences between minors and adults.

The exclusion criteria of the meta-analysis were as follows: (1) study population included minors ( $<18$ years of age); (2) nonobservational study (reviews, case reports, and clinical trials); (3) lacking effect size and 95\%CI; and (4) if multiple studies used the data from the same population, a study with the largest sample size was included in this meta-analysis.

\section{Data Extraction}

For the articles that conformed to the inclusion criteria, the data in the articles were extracted independently by two authors according to the predesigned format. The extracted data included the first author, year of publication, country, study population, study type, age, sex, sample size, number of cases, dietary intake level, effect size, and 95\%CI extracted from the most adjusted model. In case of disagreement during data extraction, the conflict would be submitted to a third author for adjudication.

\section{Quality Assessment}

Each study was evaluated by two authors and handed over to a third party for adjudication in case of disagreement. As 
the included articles were observational studies, the NewcastleOttawa scale (NOS) was used to evaluate the quality of the study and the possible risk of bias (21).

\section{Statistical Analysis}

For the current meta-analysis, we conducted a meta-analysis based on the effect size and 95\%CI between the highest quantile and the lowest or reference quantile of dietary intakes. Heterogeneity between studies was assessed by $I^{2}$ statistics. If the heterogeneity was not statistically significant $\left(I^{2}<50 \%\right.$ and $p>0.10)$, the fixed-effects model was used to combine the effect size and 95\%CI. Otherwise, the random-effects model was used. We conducted a subgroup analysis to determine whether the heterogeneity of the study came from the study type (case-control study and cohort study), the study population (European population, American population, etc.), and the study quality ( $>7$ points, $\leq 7$ points), to explore the potential sources of heterogeneity. We performed a sensitivity analysis. We successively omitted one study at a time to assess each study's relative impact on the total effect size estimation. Different statistical models (fixed-effects and random-effects model) were used to estimate effect size. Egger's test and Begg's test were used to detect publication bias.

Subsequently, for dietary factors with significant results in the analysis of extreme categories, we also explored the doseresponse relationship between dietary intakes and glioma risk. The method developed by Greenland and Longnecker was used to analyze the dose-response relationship in this study (22). For this method, we need to extract at least three groups of dietary intakes, number of participants, number of cases, effect size, and $95 \% \mathrm{CI}$ for each type of dietary factors in each study. For differences of measurement used in different studies, we calculated and unified them into cups (coffee and tea, 1 cup $=8$ ounce) or grams (other dietary factors). For each study, the median or average dietary intake corresponding to each group was used for risk estimation. If the median or average dietary intake of each group was not provided, the midpoint of the upper and lower limits of each group should be designated as the average exposure level. If the highest group was open, we assumed that the interval width was the same as the second highest category. $Q$-value was applied to assess between-study heterogeneity.

Stata 14.0 was used for all statistical analyses. Unless otherwise noted, $p<0.05$ was considered as statistically significant.

\section{RESULTS}

\section{Study Characteristics}

Figure 1 shows the article screening process of this study. A total of 6,741 articles were retrieved, including 383 from the Cochrane Library, 1,064 from the PubMed, 3,676 from the Web of Science, 1,617 from EMBASE, and 1 from other sources. After excluding duplicates between different databases, titles and abstracts of 4,795 articles were reviewed. A total of 4,704 articles were excluded because they were not related to the aim of this study. Non-observational studies and animal/cell experiments or reviews were excluded. Then, 91 articles were reviewed in full text, and 58 articles were excluded due to adolescent research, lacking effect size, and the duplication of the study population. A total of 33 articles were included.

Table 1 presents a summary of the 33 articles and characteristics included in this meta-analysis (9$12,14,15,17,18,23-47)$. All studies included 3,606,015 controls and 8,831 patients with glioma. Most participants were 18-80 years old, and each study included two sex groups. The included studies were mainly concentrated in America and Europe (Britain, France, Germany, and Sweden), and a few studies were completed by Canada, Australia, China, Japan, and Iran, including 18 case-control studies and 15 cohort studies. These studies provide glioma-related results for a total of 12 food groups: coffee, tea (black tea, green tea, and herbal tea), total vegetables, green vegetables (broccoli and green leafy vegetables such as spinach, silver beet, and lettuce), orange vegetables (pumpkin, carrot, tomato, etc.), grains, processed meats (grilled, smoked, cured red, and white meats such as bacon, sausage, luncheon meats, cold cuts, smoked ham, and hot dogs), red meats, fresh fish, processed fish (salt fish, smoked fish, pickled fish), total fruits, and citrus fruits. Around $50 \%$ of the studies had a NOS score of 8 or more.

\section{Effect Size Estimations of the Risk for the Association Between Dietary Factors and Glioma}

Effect size estimations between all dietary intakes and the risk of glioma are presented in Table 2. Compared with the lowest intakes, the highest intakes of tea $(\mathrm{RR}=0.82,95 \% \mathrm{CI}: 0.71-0.93$, $I^{2}=23.2 \%, P_{\text {forheterogeneity }}=0.230$ ) (Supplementary Figure 1), total vegetables $\left(\mathrm{RR}=0.84,95 \% \mathrm{CI}: 0.70-1.00, I^{2}=53.4 \%\right.$, $\left.P_{\text {forheterogeneity }}=0.029\right) \quad($ Supplementary Figure 2$)$, green vegetables $\left(\mathrm{RR}=0.80,95 \% \mathrm{CI}: 0.66-0.98, I^{2}=0, P_{\text {forheterogeneity }}=\right.$ 0.823) (Supplementary Figure 3), and orange vegetables $\left(\mathrm{RR}=0.79, \quad 95 \% \mathrm{CI}: \quad 0.66-0.96, I^{2}=0, \quad P_{\text {forheterogeneity }}=\right.$ 0.422) (Supplementary Figure 4) significantly reduced the risk of glioma, while the highest intakes of grains $\left(R R=1.39,95 \% \mathrm{CI}: 1.16-1.66, I^{2}=21.0, P_{\text {forheterogeneity }}=\right.$ $0.281)$ (Supplementary Figure 5), processed meats $(R R=$ 1.19, 95\%CI: $\left.1.00-1.42, I^{2}=46.4, \quad P_{\text {forheterogeneity }}=0.019\right)$ (Supplementary Figure 6), and processed fish $(R R=$ 1.37, 95\%CI: $\left.1.03-1.84, \quad I^{2}=0, \quad P_{\text {forheterogeneity }}=0.896\right)$ (Supplementary Figure 7) significantly increased the risk of glioma. However, the results of coffee, red meats, total fruits, citrus fruits, and fresh fish showed that they were not related to the incidence of glioma (Supplementary Figures 8-12).

\section{Subgroup Analysis}

For the study type, tea was statistically significant in a cohort subgroup $(R R=0.81,95 \% \mathrm{CI}: 0.71-0.93)$. Total vegetables were statistically significant in the case-control subgroup $(R R=0.76$, 95\%CI: $0.67-0.87)$. The heterogeneity of total vegetables in the subgroup analysis of study type decreased from 53.4 to $11.0 \%$. For the study population, tea was statistically significant in the American population $(R R=0.82,95 \% \mathrm{CI}$ : $0.68-0.98)$, total vegetables were statistically significant in the European 


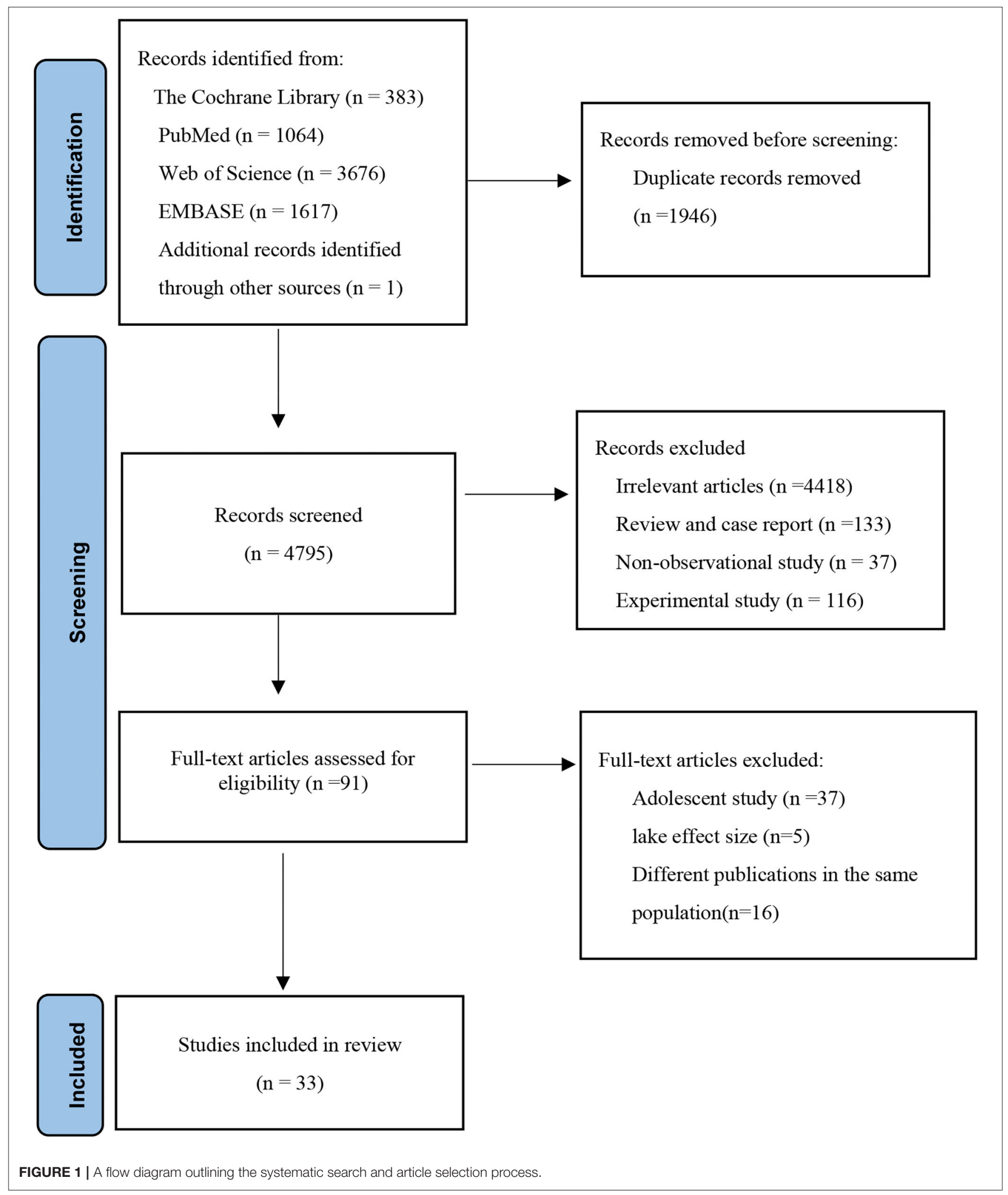


TABLE 1 | Characteristics of studies investigating the association between dietary factors and glioma.

\begin{tabular}{|c|c|c|c|c|c|c|c|c|c|}
\hline References & Year & Country & Study type & Age & Sample size & Cases & Dietary factors & $\begin{array}{l}\text { Effect size } \\
(95 \% \mathrm{Cl})\end{array}$ & $\begin{array}{l}\text { Quality } \\
\text { score }\end{array}$ \\
\hline \multirow[t]{2}{*}{ Ahlbom et al. (23) } & 1986 & Sweden & Case-control & $20-75$ & 275 & 78 & Processed meats & $1.81(1.16-2.83)$ & 8 \\
\hline & & & & & & & Processed fish & $0.90(0.30-2.50)$ & \\
\hline \multirow[t]{6}{*}{ Burch et al. (24) } & 1987 & Canada & Case-control & $25-80$ & 360 & 180 & Coffee & $1.40(0.76-2.58)$ & 7 \\
\hline & & & & & & & Tea & $1.26(0.70-2.25)$ & \\
\hline & & & & & & & Processed meats & $0.50(0.23-1.07)$ & \\
\hline & & & & & & & Processed fish & $1.67(0.61-4.59)$ & \\
\hline & & & & & & & Total fruits & $0.35(0.18-0.71)$ & \\
\hline & & & & & & & Citrus fruits & $0.56(0.32-0.98)$ & \\
\hline \multirow[t]{3}{*}{ Mills et al. (25) } & 1989 & America & Cohort & $>25$ & 34,000 & 20 & Processed meats & $2.29(0.51-7.77)$ & 8 \\
\hline & & & & & & & Total fruits & $0.85(0.28-2.60)$ & \\
\hline & & & & & & & Citrus fruits & $0.92(0.37-2.37)$ & \\
\hline \multirow{2}{*}{$\begin{array}{l}\text { Hochberg et al. } \\
\text { (15) }\end{array}$} & 1990 & America & Case-control & $18-81$ & 288 & 160 & Coffee & $0.90(0.50-1.80)$ & 7 \\
\hline & & & & & & & Processed meats & $1.00(0.60-1.60)$ & \\
\hline $\begin{array}{l}\text { Preston-Martin et } \\
\text { al. (26) }\end{array}$ & 1991 & America & Case-control & $25-69$ & 404 & 202 & Processed meats & $1.00(0.20-4.20)$ & 6 \\
\hline \multirow[t]{4}{*}{ Boeing et al. (27) } & 1993 & Germany & Case-control & $25-75$ & 520 & 105 & Total vegetables & $0.90(0.50-1.70)$ & 7 \\
\hline & & & & & & & Processed meats & $2.10(1.10-4.00)$ & \\
\hline & & & & & & & Processed fish & $1.40(0.80-2.40)$ & \\
\hline & & & & & & & Total fruits & $1.10(0.60-1.90)$ & \\
\hline \multirow[t]{8}{*}{ Gile et al. (12) } & 1994 & Australia & Case-control & $20-70$ & 818 & 409 & Total vegetables & $0.75(0.40-1.41)$ & 7 \\
\hline & & & & & & & Green vegetables & $0.86(0.61-1.22)$ & \\
\hline & & & & & & & Orange vegetables & $0.94(0.65-1.35)$ & \\
\hline & & & & & & & Processed meats & $1.31(0.92-1.86)$ & \\
\hline & & & & & & & Grains & $1.17(0.68-2.01)$ & \\
\hline & & & & & & & Fresh fish & $0.94(0.47-1.89)$ & \\
\hline & & & & & & & Processed fish & $1.31(0.84-2.06)$ & \\
\hline & & & & & & & Total fruits & $1.06(0.49-2.27)$ & \\
\hline \multirow[t]{4}{*}{ Blowers et al. (11) } & 1997 & America & Case-control & $25-74$ & 188 & 94 & Total vegetables & $1.30(0.50-3.20)$ & 7 \\
\hline & & & & & & & Processed meats & $1.70(0.80-3.80)$ & \\
\hline & & & & & & & Grains & $2.80(1.20-6.50)$ & \\
\hline & & & & & & & Fresh fish & $0.40(0.20-1.10)$ & \\
\hline
\end{tabular}


TABLE 1 | Continued

\begin{tabular}{|c|c|c|c|c|c|c|c|c|c|}
\hline References & Year & Country & Study type & Age & Sample size & Cases & Dietary factors & $\begin{array}{l}\text { Effect size } \\
(95 \% \mathrm{Cl})\end{array}$ & $\begin{array}{l}\text { Quality } \\
\text { score }\end{array}$ \\
\hline & & & & & & & Processed fish & $1.70(0.80-3.80)$ & \\
\hline & & & & & & & Total fruits & $1.30(0.50-3.00)$ & \\
\hline & & & & & & & Citrus fruits & $1.70(0.70-4.30)$ & \\
\hline Lee et al. (28) & 1997 & America & Case-control & $>20$ & 866 & 428 & Processed meats & $1.76(1.18-2.64)$ & 8 \\
\hline \multirow[t]{2}{*}{ Hu et al. (29) } & 1998 & China & Case-control & 39.6 & 654 & 218 & Total vegetables & $0.51(0.29-0.89)$ & 6 \\
\hline & & & & & & & Total fruits & $0.28(0.16-0.51)$ & \\
\hline $\begin{array}{l}\text { Schwartzbaum et } \\
\text { al. (30) }\end{array}$ & 1999 & America & Case-control & 44.9 & 80 & 40 & Processed meats & $2.30(0.80-6.70)$ & 7 \\
\hline \multirow[t]{2}{*}{ Xu et al. (31) } & 1999 & China & Case-control & $\geq 18$ & 258 & 86 & Total vegetables & $0.81(0.73-0.89)$ & 7 \\
\hline & & & & & & & Total fruits & $0.70(0.54-0.91)$ & \\
\hline \multirow[t]{7}{*}{ Chen et al. (10) } & 2002 & America & Case-control & $\geq 21$ & 685 & 236 & Total vegetables & $0.50(0.30-1.00)$ & 7 \\
\hline & & & & & & & Green vegetables & $0.70(0.40-1.20)$ & \\
\hline & & & & & & & Orange vegetables & $0.60(0.30-1.00)$ & \\
\hline & & & & & & & Processed meats & $1.10(0.60-2.10)$ & \\
\hline & & & & & & & Grains & $1.50(0.90-2.50)$ & \\
\hline & & & & & & & Red meats & $0.90(0.50-1.60)$ & \\
\hline & & & & & & & Citrus fruits & $1.00(0.60-1.70)$ & \\
\hline Efird et al. (32) & 2004 & America & Cohort & $>25$ & $1,29,393$ & 122 & Coffee & $1.70(0.80-3.60)$ & 7 \\
\hline Rollison et al. (33) & 2004 & America & Case-control & & 43 & 15 & Processed meats & $3.72(0.51-27.16)$ & 6 \\
\hline \multirow[t]{4}{*}{ Holick et al. (34) } & 2007 & America & Cohort & $25-75$ & $2,29,638$ & 296 & Total vegetables & $1.17(0.78-1.75)$ & 8 \\
\hline & & & & & & & Orange vegetables & $0.91(0.61-1.35)$ & \\
\hline & & & & & & & Total fruits & $1.41(0.95-2.10)$ & \\
\hline & & & & & & & Citrus fruits & $1.40(0.93-2.13)$ & \\
\hline \multirow[t]{2}{*}{ Michaud et al. (35) } & 2009 & America & Cohort & $25-75$ & $2,30,655$ & 335 & Processed meats & $0.92(0.48-1.77)$ & 8 \\
\hline & & & & & & & Red meats & $1.09(0.62-1.93)$ & \\
\hline \multirow[t]{8}{*}{ Terry et al. (9) } & 2009 & America & Case-control & $20-80$ & 3,671 & 1,185 & Total vegetables & $0.70(0.50-0.90)$ & 7 \\
\hline & & & & & & & Green vegetables & $0.80(0.60-1.00)$ & \\
\hline & & & & & & & Orange vegetables & $0.70(0.50-0.90)$ & \\
\hline & & & & & & & Processed meats & $0.90(0.70-1.20)$ & \\
\hline & & & & & & & Red meats & $1.30(1.00-1.70)$ & \\
\hline & & & & & & & Grains & $1.30(1.10-1.70)$ & \\
\hline & & & & & & & Fresh fish & $0.90(0.70-1.10)$ & \\
\hline & & & & & & & Citrus fruits & $1.40(1.10-1.80)$ & \\
\hline \multirow[t]{2}{*}{ Michaud et al. (36) } & 2010 & Britain & Cohort & $20-70$ & $4,10,970$ & 343 & Coffee & $0.98(0.67-1.41)$ & 9 \\
\hline & & & & & & & Tea & $1.05(0.75-1.48)$ & \\
\hline Dubrow et al. (37) & 2010 & America & Cohort & $50-71$ & $5,45,770$ & 585 & Total vegetables & $1.17(0.89-1.53)$ & 7 \\
\hline
\end{tabular}


TABLE 1 | Continued

\begin{tabular}{|c|c|c|c|c|c|c|c|c|c|}
\hline References & Year & Country & Study type & Age & Sample size & Cases & Dietary factors & $\begin{array}{l}\text { Effect size } \\
(95 \% \mathrm{Cl})\end{array}$ & $\begin{array}{l}\text { Quality } \\
\text { score }\end{array}$ \\
\hline & & & & & & & Processed meats & $1.05(0.80-1.37)$ & \\
\hline & & & & & & & Red meats & $0.85(0.65-1.11)$ & \\
\hline & & & & & & & Total fruits & $1.16(0.89-1.52)$ & \\
\hline \multirow[t]{2}{*}{ Holick et al. (38) } & 2010 & America & Cohort & $25-75$ & $2,19,515$ & 335 & Coffee & $0.80(0.54-1.17)$ & 8 \\
\hline & & & & & & & Tea & $0.71(0.45-1.12)$ & \\
\hline Baglietto et al. (39) & 2011 & Australia & Cohort & $27-81$ & 39766 & 67 & Coffee & $0.51(0.23-1.10)$ & 8 \\
\hline $\begin{array}{l}\text { Cabaniols et al. } \\
\text { (40) }\end{array}$ & 2011 & France & Case-control & $\geq 18$ & 244 & 122 & Total fruits & $0.85(0.49-1.47)$ & 7 \\
\hline \multirow[t]{2}{*}{ Dubrow et al. (41) } & 2012 & America & Cohort & $50-71$ & $5,43,006$ & 901 & Coffee & $0.95(0.64-1.41)$ & 7 \\
\hline & & & & & & & Tea & $0.75(0.57-0.99)$ & \\
\hline \multirow[t]{2}{*}{ Nelson et al. (42) } & 2012 & America & Cohort & $45-68$ & 8,006 & 9 & Coffee & $0.89(0.08-10.02)$ & 8 \\
\hline & & & & & & & Tea & $1.21(0.22-6.76)$ & \\
\hline \multirow{2}{*}{$\begin{array}{l}\text { Shayanfar et al. } \\
\text { (43) }\end{array}$} & 2013 & Iran & Case-control & $20-75$ & 384 & 128 & Processed meats & $0.54(0.25-1.14)$ & 7 \\
\hline & & & & & & & Red meats & $2.50(0.85-5.45)$ & \\
\hline \multirow[t]{2}{*}{ Hashibe et al. (44) } & 2015 & America & Cohort & $55-74$ & 97,334 & 103 & Coffee & $0.76(0.50-1.17)$ & 8 \\
\hline & & & & & & & Tea & $1.04(0.65-1.66)$ & \\
\hline \multirow[t]{2}{*}{ Ogawa et al. (45) } & 2016 & Japan & Cohort & $40-69$ & $1,01,984$ & 61 & Coffee & $0.55(0.17-1.84)$ & 8 \\
\hline & & & & & & & Tea & $1.05(0.54-2.05)$ & \\
\hline \multirow[t]{2}{*}{ Ward et al. (14) } & 2018 & Britain & Cohort & $25-70$ & $4,09,248$ & 688 & Processed meats & $1.12(0.83-1.51)$ & 7 \\
\hline & & & & & & & Red meats & $0.99(0.75-1.31)$ & \\
\hline \multirow[t]{2}{*}{ Malmir et al. (46) } & 2019 & Iran & Case-control & $20-75$ & 384 & 128 & Coffee & $0.09(0.03-0.24)$ & 8 \\
\hline & & & & & & & Tea & $0.33(0.13-0.86)$ & \\
\hline \multirow[t]{2}{*}{ Cote et al. (18) } & 2020 & America & Cohort & $25-75$ & $2,37,516$ & 554 & Coffee & $0.96(0.66-1.37)$ & 8 \\
\hline & & & & & & & Tea & $0.73(0.49-1.10)$ & \\
\hline \multirow[t]{2}{*}{ Creed et al. (17) } & 2020 & Britain & Cohort & $40-69$ & $3,67,539$ & 470 & Coffee & $0.71(0.49-1.05)$ & 8 \\
\hline & & & & & & & Tea & $0.69(0.51-0.94)$ & \\
\hline $\begin{array}{l}\text { Shahrestani et al. } \\
\text { (47) }\end{array}$ & 2021 & Iran & Case-control & $20-75$ & 384 & 128 & Grains & $2.46(1.01-5.97)$ & 8 \\
\hline
\end{tabular}


TABLE 2 | A meta-analysis for the association between dietary factors and glioma.

\begin{tabular}{|c|c|c|c|c|}
\hline Dietary factors & Number of studies & RR (95\%Cl) & $I^{2}(\%)$ & $\boldsymbol{P}_{\text {forheterogeneity }}$ \\
\hline Coffee & 12 & $0.81(0.62-1.06)$ & 61.2 & 0.003 \\
\hline Tea & 10 & $0.82(0.71-0.93)$ & 23.2 & 0.230 \\
\hline Total vegetables & 9 & $0.84(0.70-1.00)$ & 53.4 & 0.029 \\
\hline Green vegetables & 3 & $0.80(0.66-0.98)$ & 0 & 0.823 \\
\hline Orange vegetables & 4 & $0.79(0.66-0.96)$ & 0 & 0.422 \\
\hline Processed meats & 17 & $1.19(1.00-1.42)$ & 46.4 & 0.019 \\
\hline Red meats & 6 & $1.05(0.91-1.21)$ & 42.5 & 0.122 \\
\hline Grains & 5 & 1.39 (1.16-1.66) & 21.0 & 0.281 \\
\hline Fresh fish & 3 & $0.86(0.70-1.06)$ & 39.7 & 0.190 \\
\hline Processed fish & 5 & 1.37 (1.03-1.84) & 0 & 0.896 \\
\hline Total fruits & 10 & $0.82(0.59-1.12)$ & 75.0 & $<0.001$ \\
\hline Citrus fruits & 6 & $1.12(0.83-1.52)$ & 52.3 & 0.063 \\
\hline
\end{tabular}

population $(R R=0.73,95 \% \mathrm{CI}: 0.56-0.96)$ and other populations $(R R=0.76,95 \% \mathrm{CI}: 0.61-0.94)$. Grains were statistically significant in the American population $(R R=1.77,95 \% \mathrm{CI}: 1.15-$ 2.74 ) and European population ( $\mathrm{RR}=1.30$, 95\%CI: 1.05-1.62). For study quality, tea and processed meats were statistically significant in the subgroup with the study quality score $>7$ (tea: $R R=0.81,95 \% \mathrm{CI}: 0.69-0.95$; processed meats: $R R=1.49$, 95\%CI: $1.19-1.87)$. Total vegetables and grains were statistically significant in the subgroup with the study quality score $\leq 7$ (total vegetables: $R R=0.82,95 \% \mathrm{CI}: 0.75-0.89$; grains: $R R=1.38$, 95\%CI: 1.14-1.68). The heterogeneity of processed meats in the subgroup analysis of study quality decreased from 46.4 to $37.4 \%$ (Table 3).

\section{Sensitivity Analysis and Publication Bias}

The results of the sensitivity analysis showed that the significance of the fixed-effects and random-effects model were basically the same for tea, total vegetables, green vegetables, orange vegetables, grains, processed meats, and processed fish. This suggests that the results of this meta-analysis are relatively stable (Table 4).

The impact of the individual study on the summary RR was assessed by repeating the meta-analysis after removing each study in turn (Table 4). For tea and processed meats, when Burch's study (24) was excluded, the results of all studies and glioma risk remained significant, but the heterogeneity decreased significantly (tea: $R R=0.80$, 95\%CI: $0.69-0.91, I^{2}=15.5 \%$, $P_{\text {forheterogeneity }}=0.305$, processed meats: $R R=1.23,95 \% \mathrm{CI}: 1.04-$ $\left.1.46, I^{2}=40.4 \%, P_{\text {forheterogeneity }}=0.048\right)$. Similarly, excluding one grain study (11), the overall results on glioma risk were still significant, and the heterogeneity was significantly reduced $(R R$ $=1.34,95 \% \mathrm{CI}: 1.12-1.62, I^{2}=0, P_{\text {forheterogeneity }}=0.513$ ). It was speculated that these two studies might be the main reason for the heterogeneity of related dietary factors and glioma risk results.

Publication bias was evaluated by Begg's rank correlation method and Egger's regression test. The $p$-value of publication bias of all dietary intakes was $>0.1$, suggesting that the difference was not statistically significant, so the publication bias was not obvious in this study (Table 4).

\section{Dose-Response Relationship}

Due to the limited number of available articles, only tea, total vegetables, orange vegetables, and processed meats could be analyzed for the dose-response relationship from 10 articles. The dose-response relationship between various dietary factors and the risk of glioma was shown in Figure 2. There was a significant linear dose-response relationship between tea and glioma, and increasing the intake of a cup of tea every day reduced the risk of glioma by $4 \%\left(P_{-n o n l i n e a r i t y}=0.166, \mathrm{RR}=0.96,95 \% \mathrm{CI}\right.$ : $0.94-$ $0.99)$. Although total vegetables, orange vegetables, and processed meats had similar linear trends, the results were not significant due to an insufficient number of studies.

\section{DISCUSSION}

Based on 33 observational studies on dietary factors and glioma published from 1986 to 2021, involving 3,606,015 controls and 8,831 patients, our meta-analysis results showed that higher intakes of tea, total vegetables, green vegetables, and orange vegetables could significantly reduce the risk of glioma, while higher intakes of processed meats, grains, and processed fish could significantly increase the risk of glioma. However, coffee, red meats, fresh fish, fruits, and citrus fruits had no significant effect on the risk of glioma. For the results of the dose-response relationship, increasing the intake of a cup of tea per day could reduce the risk of glioma by $4 \%$. Although there was a similar linear trend between total vegetables, orange vegetables, and processed meats and the risk of glioma, and the results were not significant. This may be due to the availability of a limited number of articles that investigate the dose-response relationship of these dietary factors on glioma.

We conducted a subgroup analysis of dietary factors with significant results due to the study population, study type, and study quality to explore the sources of heterogeneity. Although the overall heterogeneity of vegetables and gliomas was not high, it was found through a subgroup analysis that the difference of study types may be the main source of heterogeneity. Seven of the nine studies were case-control studies. Recall bias resulting from dietary survey methods in the case-control studies must 
TABLE 3 | A subgroup analysis for the association between dietary factors and glioma.

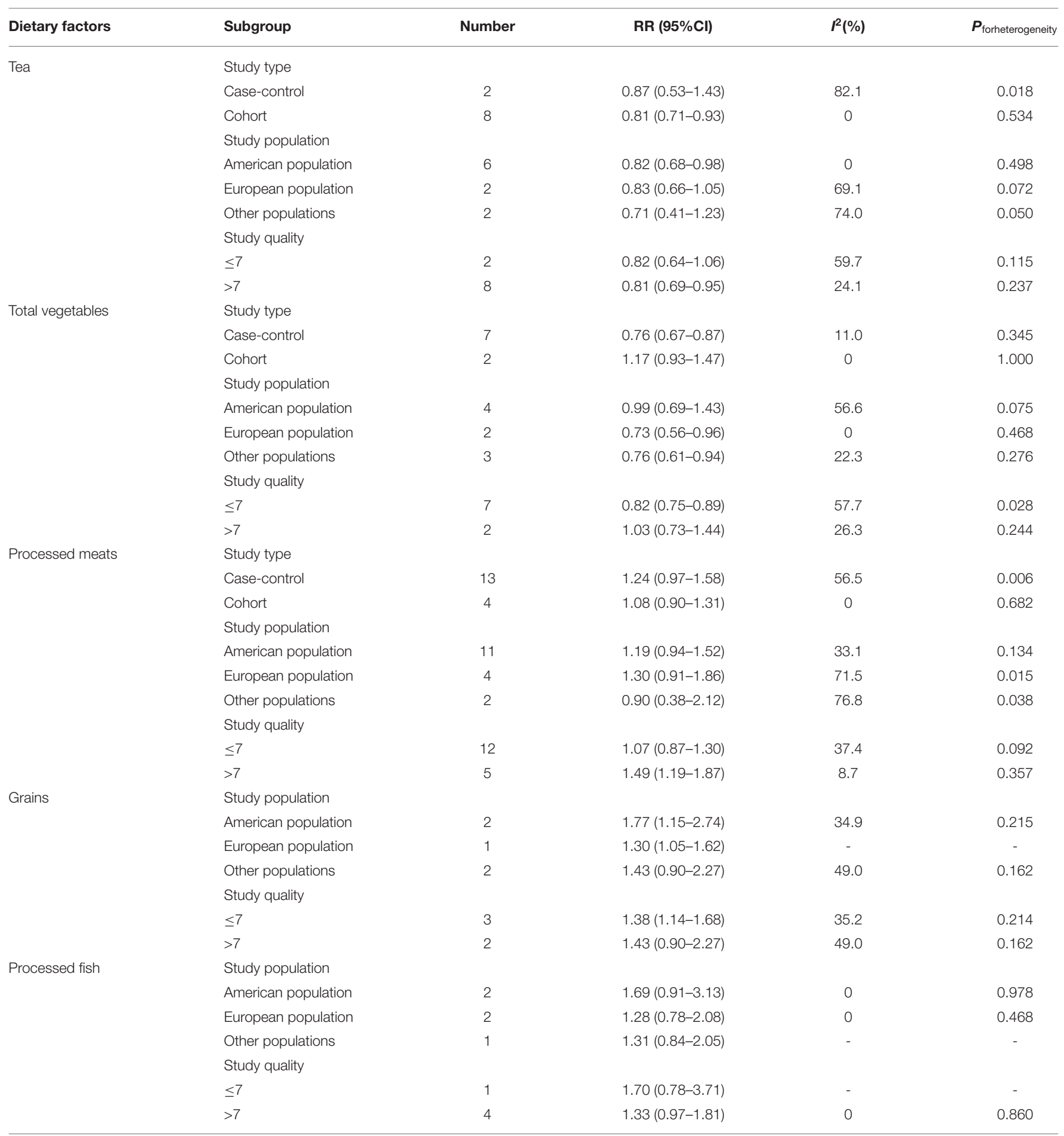

be considered. There were only two cohort studies, which limit the significance of the combined results to a certain extent. The heterogeneity of processed meats mainly came from the difference in the study quality. The articles with a score of $<7$ still had $34.7 \%$ heterogeneity after merging. In addition, the exploration of influencing factors of glioma in the Burch study focused more on environmental exposures, such as smoking, water source, and x-ray exposure. It did not adopt appropriate investigation methods to systematically investigate the dietary intakes of the subjects but only provided a small number of dietary data such as tea and processed meats. Moreover, the cases in this study were not newly diagnosed, and the recall 
TABLE 4 | Sensitivity analysis and publication bias.

\begin{tabular}{lcccc}
\hline Dietary factors & Fixed-effects model & Random-effects model & Influential analysis & Egger's test \\
\hline Coffee & $0.84(0.74-0.99)$ & $0.81(0.62-1.06)$ & $0.58-1.11$ & 0.319 \\
Tea & $0.82(0.71-0.93)$ & $0.82(0.70-1.00)$ & $0.67-0.99$ & 0.780 \\
Total vegetables & $0.83(0.76-0.90)$ & $0.84(0.70-1.00)$ & $0.64-1.08$ & 0.969 \\
Red meats & $1.05(0.91-1.21)$ & $1.06(0.86-1.31)$ & $0.81-1.36$ & 0.466 \\
Processed meats & $1.16(1.03-1.30)$ & $1.19(1.00-1.42)$ & $0.96-1.49$ & 0.858 \\
Grains & $1.39(1.16-1.66)$ & $1.45(1.14-1.85)$ & $1.12-2.20$ & 1.000 \\
Fresh fish & $0.86(0.70-1.06)$ & $0.79(0.53-1.18)$ & $0.39-1.15$ & 0.136 \\
Processed fish & $1.37(1.03-1.84)$ & $1.37(1.03-1.84)$ & $0.97-2.08$ & 0.531 \\
Total fruits & $0.87(0.76-1.00)$ & $0.82(0.59-1.12)$ & $0.54-1.21$ & 0.997 \\
Citrus fruits & $1.22(1.02-1.45)$ & $1.12(0.83-1.52)$ & $0.70-1.64$ & 0.221 \\
Green vegetables & $0.80(0.66-0.98)$ & $0.80(0.66-0.98)$ & $0.60-1.09$ & 0.296 \\
Orange vegetables & $0.79(0.66-0.96)$ & $0.79(0.66-0.96)$ & $0.60-1.10$ & 0.377 \\
\end{tabular}
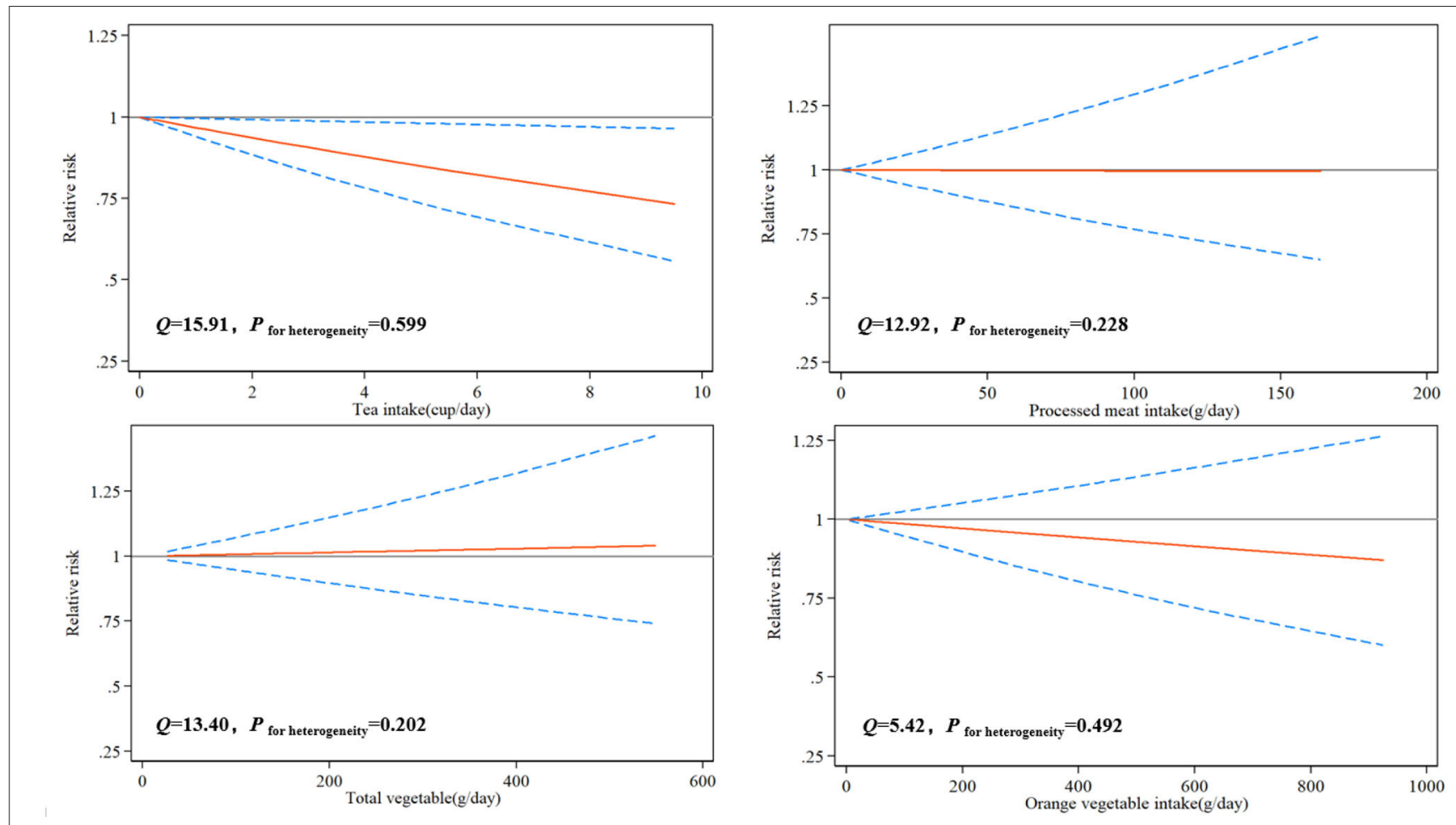

FIGURE 2 | Risk between dietary factors and glioma estimates from the dose-response meta-analysis.

bias was large. These factors may explain the heterogeneity in the studies involving tea and processed meats. Similarly, Blowers et al. also contributed most of the heterogeneity to the metaanalysis of cereals and gliomas. The study had a small sample size of only 94 cases. The heterogeneity of green vegetables, orange vegetables, and processed fish was very small. Because the number of studies was small, there was no subgroup analysis. In the sensitivity analysis, the dietary factors with significant results were consistent in the two models. No publication bias was found in all studies, which suggested that the research results were relatively stable.
Creed et al. found that drinking 4 cups or more of tea each day was associated with a reduction of the risk of glioma [hazard ratio $(\mathrm{HR})=0.69,95 \% \mathrm{CI}: 0.51-0.94]$ and had the same effect on glioblastoma ( $\mathrm{HR}=0.93$ per 1 cup/day increment; $95 \% \mathrm{CI}$ : $0.89-0.98$ ), which was consistent with our results (17). For a long time, a few studies demonstrated that polyphenols in tea prevented cancer by enhancing cell antioxidant capacity and regulating epigenetic aberrations in DNA methylation, histone modification, and microRNA formation (48). Epigallocatechin gallate has especially attracted attention. A few studies showed that epigallocatechin gallate could induce cell death, prevent 
cell proliferation, and limit the invasion of a variety of glioma cell lines (49). Experimental results in mice also showed that epigallocatechin gallate could enhance the therapeutic effect of temozolomide on glioma (50). Similarly, the protective effect of vegetables against glioma may be related to antioxidant effects. Chen et al.'s study found that the consumption frequency per week of orange vegetables and green vegetables was 0.1 and 0.09 times higher in the control group than that in patients with glioma (10). Vegetables contain many antioxidants such as vitamins, isothiocyanates, glucosinolates, and dietary fibers. Compared with other vegetables, dark green leafy vegetables and orange vegetables are high in the carotenoids we turn into vitamin A (51). Carotenoids are also antioxidants. A metaanalysis of seven articles showed that the highest category of dietary vitamin A was significantly associated with the reduced risk of glioma ( $R R=0.80,95 \% \mathrm{CI}$ : 0.62-0.98) (52). These antioxidants can activate methylation-silenced genes in cancer cells, such as O6 methylguanine DNA methyltransferase (MGMT). The gene polymorphism of MGMT is associated with the risk of glioma, whereas increased MGMT activation is thought to prevent glioma progression $(36,53)$. In addition, the meta-analysis by Micek et al. found a significant negative correlation between dietary intakes of phytoestrogens (such as isoflavones and lignans) and the recurrence of cancer through a meta-analysis. In patients with grade III glioma, higher dietary intakes of lignans were associated with a better cancer survival rate $(H R=0.48,95 \% \mathrm{CI}$ : 0.25-0.92) (54). So far, however, there was no prospective study to prove that vegetables can reduce the risk of glioma. There are a few studies on specific vegetables and the risk of glioma. Moreover, no similar results were found in the correlation analysis between fruits and glioma. The specific reasons need to be further explored. In future studies, it is necessary to obtain more detailed vegetable and fruit consumption history through dietary investigation, and to conduct more accurate research on the potential protective effect of specific vegetables and fruits against gliomas. Compared with red meats and fresh fish, processed meats and processed fish have a more negative effect on glioma. Processed meats and fish carry more carcinogens during processing and preservation, such as heterocyclic amines, polycyclic aromatic hydrocarbons, and $\mathrm{N}$ nitroso compounds (55). Animal experiments have confirmed that $\mathrm{N}$-nitroso compounds can induce glioma by reducing the repair efficiency after DNA damage $(56,57)$. Exposures to $\mathrm{N}$ nitroso compounds during the prenatal period can result in an offspring with brain tumors (58). However, no significant association was found in prospective studies on $\mathrm{N}$-nitroso compounds and gliomas (nitrate: $R R=1.02$; 95\%CI: 0.66 , 1.58; nitrite: $R R=1.26$; 95\%CI: $0.89,1.79$ ) (34). However, we must consider that the source of $\mathrm{N}$-nitroso compounds is not limited to processed food, but also drinking water, smoking, and occupational exposure. Exploring the correlation between the exposure level of related compounds in the human body and the risk of glioma may effectively solve this problem. Furthermore, processed meats and fish have increased levels of saturated fatty acids and decreased levels of the beneficial unsaturated fatty acids (59). Some studies have shown that the growth and diffusion of glioma are related to fatty acid metabolism in vivo
(60), and unsaturated fatty acids have a certain cytotoxic effect on glioma cells (61). Epidemiological studies show that dietary intakes of polyunsaturated fatty acids are negatively correlated with the risk of glioma ( $O R=0.20$; 95\%CI: 0.05-0.84) (62). This is the first meta-analysis to conclude that grains are a risk factor for glioma. Higher intakes of grains may increase the levels of insulin and insulin-like growth factor I (IGF1). Some articles have shown that the IGF-1 signaling system can promote tumor progression by preventing apoptosis and stimulating tumor cell proliferation, which may be one of the main mechanisms to increase the risk of glioma (63). Moreover, long-term intakes of grains will increase the levels of oxidative stress and inflammation, and to a certain extent promote the occurrence of tumors $(64,65)$. Although the preventive effect of coffee on glioma has been concerned by scholars, its chlorogenic acid (66), caffeine (67), and other components have been shown to have an inhibitory effect on glioma. However, this study did not find that coffee can reduce the risk of glioma, which is consistent with previous studies $(17,18)$. Due to the wide processing technology and a variety of coffees, there are great differences in the active ingredients contained in different coffees (68), which will affect the evaluation of the actual intakes of anticancer ingredients such as caffeine. Therefore, the evaluation of the relationship between coffee intakes and glioma may be limited. Finally, the impact of dietary intakes on glioma may not be caused by a single food but rather a dietary pattern. Mousavi et al. found that the Mediterranean diet had a protective effect against glioma in the Iranian population (69), and similar results were also found in a cohort study (20). However, there are still a few glioma-related studies that can evaluate the whole dietary quality.

To date, our study is the largest meta-analysis with the largest sample size that investigates dietary factors and glioma. This study has some advantages. First, this study is the first meta-analysis involving the impact of multiple dietary factors on the incidence of glioma, including 12 food groups. It is the first study to find the impact of grains, green vegetables, and orange vegetables on the incidence risk of glioma through a meta-analysis. Although the number of articles is relatively small, it provides a new scientific basis for the prevention of glioma. Secondly, the included articles were strictly screened. We rejected some studies that had been included in previous meta-analyses but involved meningiomas and other brain tumors. The source of heterogeneity is thoroughly analyzed for the significant results. All these improve the accuracy of the research results. However, this study has some limitations. First, the articles used have the publication dates that span a larger timeframe. Some long-standing articles and casecontrol studies have problems with quality, such as large recall bias and inaccurate dietary survey methods. These will inevitably impact the analysis. Additionally, as a meta-analysis of observational studies, we may not be able to control all potential confounding factors. These confounding factors may lead to a certain level of deviation. Finally, for the doseresponse relationship, only tea obtained significant results. Other dietary factors did not obtain meaningful results due to a small number of articles that were included in the analysis. In future 
research, we can improve the relevant analysis by supplementing more articles.

\section{CONCLUSION}

In summary, the current meta-analysis shows that the intakes of tea, total vegetables, green vegetables, and orange vegetables may reduce the risk of glioma, while the intakes of grains, processed meats, and processed fish may increase the risk of glioma. Therefore, the impact of dietary factors on glioma could not be ignored. In future studies, we should find a method to comprehensively evaluate dietary factors and nutrient exposure in the population, to further study the relationship between dietary factors and glioma.

\section{DATA AVAILABILITY STATEMENT}

The original contributions presented in the study are included in the article/Supplementary Material, further inquiries can be directed to the corresponding author.

\section{REFERENCES}

1. American Association of Neurological Surgeons. (2018). Available online at: https://www.aans.org/en/Patients/Neurosurgical-Conditions-andTreatments/Brain-Tumors (accessed January 09, 2022).

2. Bellail AC, Hunter SB, Brat DJ, Tan C, Van Meir EG. Microregional extracellular matrix heterogeneity in brain modulates glioma cell invasion. Int J Biochem Cell Biol. (2004) 36:1046-69. doi: 10.1016/j.biocel.2004.01.013

3. Turner MC, Krewski D, Armstrong BK, Chetrit A, Giles GG, Hours M, et al. Allergy and brain tumors in the INTERPHONE study: pooled results from Australia, Canada, France, Israel, and New Zealand. Cancer Causes Control. (2013) 24:949-60. doi: 10.1007/s10552-013-0171-7

4. Gurney JG, Preston-Martin S, McDaniel AM, Mueller BA, Holly EA. Head injury as a risk factor for brain tumors in children: results from a multicenter case-control study. Epidemiology. (1996) 7:4859. doi: 10.1097/00001648-199609000-00006

5. Mathews JD, Forsythe AV, Brady Z, Butler MW, Goergen SK, Byrnes GB, et al. Cancer risk in 680,000 people exposed to computed tomography scans in childhood or adolescence: data linkage study of 11 million Australians. BMJ. (2013) 346:f2360. doi: 10.1136/bmj.f2360

6. Bielecka J, Markiewicz-Zukowska R. The influence of nutritional and lifestyle factors on glioma incidence. Nutrients. (2020) 12:1812. doi: 10.3390/nu12061812

7. Voss M, Wagner M, von Mettenheim N, Harter PN, Wenger KJ, Franz K, et al. ERGO2: a prospective, randomized trial of Calorie-Restricted ketogenic diet and fasting in addition to reirradiation for malignant glioma. Int J Radiat Oncol Biol Phys. (2020) 108:987-95. doi: 10.1016/j.ijrobp.2020.06.021

8. Schwartz K, Chang HT, Nikolai M, Pernicone J, Rhee S, Olson K, et al. Treatment of glioma patients with ketogenic diets: report of two cases treated with an IRB-approved energy-restricted ketogenic diet protocol and review of the literature. Cancer Metab. (2015) 3:3. doi: 10.1186/s40170-015-0129-1

9. Terry MB, Howe G, Pogoda JM, Zhang FF, Ahlbom A, Choi W, et al. An international case-control study of adult diet and brain tumor risk: a histology-specific analysis by food group. Ann Epidemiol. (2009) 19:16171. doi: 10.1016/j.annepidem.2008.12.010

10. Chen H, Ward MH, Tucker KL, Graubard BI, McComb RD, Potischman NA, et al. Diet and risk of adult glioma in eastern Nebraska, United States. Cancer Causes Control. (2002) 13:647-55. doi: 10.1023/A:1019527225197

11. Blowers L, Preston-Martin S, Mack WJ. Dietary and other lifestyle factors of women with brain gliomas in Los Angeles County (California, USA). Cancer Causes Control. (1997) 8:5-12. doi: 10.1023/A:1018437031987

\section{AUTHOR CONTRIBUTIONS}

WL and WZ contributed to the conception or design of the work. $\mathrm{WZ}$ and JJ contributed to searching the databases. WZ, JJ, and YH contributed to the acquisition, analysis, or interpretation of data for the work. WZ and XL performed proofreading and modified the language. XL and FC reviewed and edited the manuscript. All authors have read and approved the final manuscript.

\section{FUNDING}

This study was supported by the National Natural Science Foundation of Beijing (No. J200003) and National Science and Technology Major Project of China (No. 2016ZX09101017).

\section{SUPPLEMENTARY MATERIAL}

The Supplementary Material for this article can be found online at: https://www.frontiersin.org/articles/10.3389/fnut.2022. 834258/full\#supplementary-material

12. Giles GG, McNeil JJ, Donnan G, Webley C, Staples MP, Ireland PD, et al. Dietary factors and the risk of glioma in adults: results of a case-control study in Melbourne, Australia. Int J Cancer. (1994) 59:35762. doi: 10.1002/ijc.2910590311

13. Zhang Z, Xin J. Dietary fresh fish and processed fish intake and the risk of glioma: a meta-analysis of observational studies. Cell Mol Biol (Noisy-legrand). (2019) 65:48-53. doi: 10.14715/cmb/2019.65.8.8

14. Ward HA, Gayle A, Jakszyn P, Merritt M, Melin B, Freisling H, et al. Meat and haem iron intake in relation to glioma in the European Prospective Investigation into Cancer and Nutrition study. Eur J Cancer Prev. (2018) 27:379-83. doi: 10.1097/CEJ.0000000000000331

15. Hochberg F, Toniolo P, Cole P, Salcman M. Nonoccupational risk indicators of glioblastoma in adults. J Neurooncol. (1990) 8:55-60. doi: 10.1007/BF00182087

16. Saneei P, Willett W, Esmaillzadeh A. Red and processed meat consumption and risk of glioma in adults: a systematic review and meta-analysis of observational studies. J Res Med Sci. (2015) 20:602-12. doi: 10.4103/1735-1995.165970

17. Creed JH, Smith-Warner SA, Gerke TA, Egan KM. A prospective study of coffee and tea consumption and the risk of glioma in the UK Biobank. Eur J Cancer. (2020) 129:123-31. doi: 10.1016/j.ejca.2020.01.012

18. Cote DJ, Bever AM, Wilson KM, Smith TR, Smith-Warner SA, Stampfer MJ, et al. Prospective study of tea and coffee intake and risk of glioma. Int J Cancer. (2020) 146:2442-9. doi: 10.1002/ijc.32574

19. Pranata R, Feraldho A, Lim MA, Henrina J, Vania R, Golden N, et al. Coffee and tea consumption and the risk of glioma: a systematic review and dose-response meta-analysis. Br J Nutr. (2021) 127:78-86. doi: 10.1017/S0007114521000830

20. Kuan AS, Green J, Kitahara CM, Berrington DGA, Key T, Reeves GK, et al. Diet and risk of glioma: Combined analysis of 3 large prospective studies in the UK and USA. Neuro Oncol. (2019) 21:944-52. doi: 10.1093/neuonc/noz013

21. Stang A. Critical evaluation of the Newcastle-Ottawa scale for the assessment of the quality of nonrandomized studies in meta-analyses. Eur J Epidemiol. (2010) 25:603-5. doi: 10.1007/s10654-010-9491-z

22. Greenland S, Longnecker MP. Methods for trend estimation from summarized dose-response data, with applications to meta-analysis. Am J Epidemiol. (1992) 135:1301-9. doi: 10.1093/oxfordjournals.aje.a1 16237

23. Ahlbom A, Navier IL, Norell S, Olin R, Spannare B. Nonoccupational risk indicators for astrocytomas in adults. Am J Epidemiol. (1986) 124:3347. doi: 10.1093/oxfordjournals.aje.a114393 
24. Burch JD, Craib KJ, Choi BC, Miller AB, Risch HA, Howe GR. An exploratory case-control study of brain tumors in adults. J Natl Cancer Inst. (1987) 78:601-9.

25. Mills PK, Preston-Martin S, Annegers JF, Beeson WL, Phillips RL, Fraser GE. Risk factors for tumors of the brain and cranial meninges in SeventhDay Adventists. Neuroepidemiology. (1989) 8:266-75. doi: 10.1159/0001 10193

26. Preston-Martin S, Mack W. Gliomas and meningiomas in men in Los Angeles County: Investigation of exposures to N-nitroso compounds. IARC Sci Publ. (1991) 105:197-203.

27. Boeing H, Schlehofer B, Blettner M, Wahrendorf J. Dietary carcinogens and the risk for glioma and meningioma in Germany. Int J Cancer. (1993) 53:561-5. doi: 10.1002/ijc.2910530406

28. Lee M, Wrensch M, Miike R. Dietary and tobacco risk factors for adult onset glioma in the San Francisco Bay Area (California, USA). Cancer Causes Control. (1997) 8:13-24. doi: 10.1023/A:1018470802969

29. Hu J, Johnson KC, Mao Y, Guo L, Zhao X, Jia X, et al. Risk factors for glioma in adults: a case-control study in northeast China. Cancer Detect Prev. (1998) 22:100-8. doi: 10.1046/j.1525-1500.1998.CDOA22.x

30. Schwartzbaum JA, Fisher JL, Goodman J, Octaviano D, Cornwell DG. Hypotheses concerning roles of dietary energy, cured meat, and serum tocopherols in adult glioma development. Neuroepidemiology. (1999) 18:15666. doi: 10.1159/000026207

31. Xu Y, Shi L, Shi L, Zhao JB, Hu JF. Diet factors associated with glioma in a case-control study. Chin J Prev Contr Chron Non-Commun Dis. (1999) 7:222-3.

32. Efird JT, Friedman GD, Sidney S, Klatsky A, Habel LA, Udaltsova NV, et al. The risk for malignant primary adult-onset glioma in a large, multiethnic, managed-care cohort: cigarette smoking and other lifestyle behaviors. $J$ Neurooncol. (2004) 68:57-69. doi: 10.1023/B:NEON.0000024746.87666.ed

33. Rollison D, Helzlsouer KJ. Processed meat consumption and adult gliomas in a Maryland cohort. Cancer Cause Control. (2004) 15:99100. doi: 10.1023/B:CACO.0000016675.85386.54

34. Holick CN, Giovannucci EL, Rosner B, Stampfer MJ, Michaud DS. Prospective study of intake of fruit, vegetables, and carotenoids and the risk of adult glioma. Am J Clin Nutr. (2007) 85:877-86. doi: 10.1093/ajcn/85.3.877

35. Michaud DS, Holick CN, Batchelor TT, Giovannucci E, Hunter DJ. Prospective study of meat intake and dietary nitrates, nitrites, and nitrosamines and risk of adult glioma. Am J Clin Nutr. (2009) 90:5707. doi: 10.3945/ajen.2008.27199

36. Michaud DS, Gallo V, Schlehofer B, Tjonneland A, Olsen A, Overvad K, et al. Coffee and tea intake and risk of brain tumors in the European Prospective Investigation into Cancer and Nutrition (EPIC) cohort study. Am J Clin Nutr. (2010) 92:1145-50. doi: 10.3945/ajcn.2010.29876

37. Dubrow R, Darefsky AS, Park Y, Mayne ST, Moore SC, Kilfoy B, et al. Dietary components related to $\mathrm{N}$-nitroso compound formation: a prospective study of adult glioma. Cancer Epidemiol Biomarkers Prev. (2010) 19:170922. doi: 10.1158/1055-9965.EPI-10-0225

38. Holick CN, Smith SG, Giovannucci E, Michaud DS. Coffee, tea, caffeine intake, and risk of adult glioma in three prospective cohort studies. Cancer Epidemiol Biomarkers Prev. (2010) 19:39-47. doi: 10.1158/1055-9965.EPI-09-0732

39. Baglietto L, Giles GG, English DR, Karahalios A, Hopper JL, Severi G. Alcohol consumption and risk of glioblastoma; evidence from the melbourne collaborative cohort study. Int J Cancer. (2011) 128:192934. doi: $10.1002 / \mathrm{ijc} .25770$

40. Cabaniols C, Giorgi R, Chinot O, Ferahta N, Spinelli V, Alla P, et al. Links between private habits, psychological stress and brain cancer: a case-control pilot study in France. J Neurooncol. (2011) 103:30716. doi: 10.1007/s11060-010-0388-1

41. Dubrow R, Darefsky AS, Freedman ND, Hollenbeck AR, Sinha R. Coffee, tea, soda, and caffeine intake in relation to risk of adult glioma in the NIH-AARP Diet and Health Study. Cancer Causes Control. (2012) 23:75768. doi: 10.1007/s10552-012-9945-6

42. Nelson JS, Burchfiel CM, Fekedulegn D, Andrew ME. Potential risk factors for incident glioblastoma multiforme: the Honolulu Heart Program and Honolulu-Asia Aging Study. J Neurooncol. (2012) 109:315-21. doi: 10.1007/s11060-012-0895-3
43. Shayanfar M, M-Shirazi M, Rashidkhani B, Esmaillzadeh A, Houshiar-Rad A, Doaei S, et al. The association between food groups and adult gliomas: a casecontrol study in adult with gliomas. J Health Syst Res. (2013) 1491-502.

44. Hashibe M, Galeone C, Buys SS, Gren L, Boffetta P, Zhang ZF, et al. Coffee, tea, caffeine intake, and the risk of cancer in the PLCO cohort. Br J Cancer. (2015) 113:809-16. doi: 10.1038/bjc.2015.276

45. Ogawa T, Sawada N, Iwasaki M, Budhathoki S, Hidaka A, Yamaji T, et al. Coffee and green tea consumption in relation to brain tumor risk in a Japanese population. Int J Cancer. (2016) 139:2714-21. doi: 10.1002/ijc.30405

46. Malmir H, Shayanfar M, Mohammad-Shirazi M, Tabibi H, Sharifi G, Esmaillzadeh A. Tea and coffee consumption in relation to glioma: a casecontrol study. Eur J Nutr. (2019) 58:103-11. doi: 10.1007/s00394-017-1575-Z

47. Shahrestani MA, Saneei P, Shayanfar M, Mohammad-Shirazi M, Sharifi G, Sadeghi O, et al. The relationship between rice consumption and glioma: a case-control study in adults. Sci Rep. (2021) 11:6073. doi: 10.1038/s41598-021-85562-2

48. Bag A, Bag N. Tea polyphenols and prevention of epigenetic aberrations in cancer. J Nat Sci Biol Med. (2018) 9:2-5. doi: 10.4103/jnsbm.JNSBM_46_17

49. Zhang Y, Wang SX, Ma JW, Li HY, Ye JC, Xie SM, et al. EGCG inhibits properties of glioma stem-like cells and synergizes with temozolomide through downregulation of P-glycoprotein inhibition. J Neurooncol. (2015) 121:41-52. doi: 10.1007/s11060-014-1604-1

50. Chen TC, Wang W, Golden EB, Thomas S, Sivakumar W, Hofman FM, et al. Green tea epigallocatechin gallate enhances therapeutic efficacy of temozolomide in orthotopic mouse glioblastoma models. Cancer Lett. (2011) 302:100-8. doi: 10.1016/j.canlet.2010.11.008

51. Serafini M, Peluso I. Functional foods for health: the interrelated antioxidant and Anti-Inflammatory role of fruits, vegetables, herbs, spices and cocoa in humans. Curr Pharm Des. (2016) 22:6701-15. doi: 10.2174/1381612823666161123094235

52. Lv W, Zhong X, Xu L, Han W. Association between dietary vitamin A intake and the risk of glioma: evidence from a meta-analysis. Nutrients. (2015) 7:8897-904. doi: 10.3390/nu7115438

53. Yu W, Zhang L, Wei Q, Shao A. O(6)-Methylguanine-DNA methyltransferase (MGMT): challenges and new opportunities in glioma chemotherapy. Front Oncol. (2019) 9:1547. doi: 10.3389/fonc.2019.01547

54. Micek A, Godos J, Brzostek T, Gniadek A, Favari C, Mena P, et al. Dietary phytoestrogens and biomarkers of their intake in relation to cancer survival and recurrence: a comprehensive systematic review with meta-analysis. Nutr Rev. (2021) 79:42-65. doi: 10.1093/nutrit/nuaa043

55. Lijinsky W. N-Nitroso compounds in the diet. Mutat Res. (1999) 443:12938. doi: 10.1016/S1383-5742(99)00015-0

56. Koestner A. Characterization of N-nitrosourea-induced tumors of the nervous system; their prospective value for studies of neurocarcinogenesis and brain tumor therapy. Toxicol Pathol. (1990) 18:186-92. doi: 10.1177/019262339001800124

57. Goth R, Rajewsky MF. Persistence of O6-ethylguanine in rat-brain DNA: Correlation with nervous system-specific carcinogenesis by ethylnitrosourea. Proc Natl Acad Sci U S A. (1974) 71:639-43. doi: 10.1073/pnas.71.3.639

58. Maekawa A, Mitsumori K. Spontaneous occurrence and chemical induction of neurogenic tumors in rats-influence of host factors and specificity of chemical structure. Crit Rev Toxicol. (1990) 20:287-310. doi: 10.3109/10408449009089866

59. Ekiz E, Oz F. The effects of different frying oils on the formation of heterocyclic aromatic amines in meatballs and the changes in fatty acid compositions of meatballs and frying oils. J Sci Food Agric. (2019) 99:150918. doi: $10.1002 /$ jsfa. 9325

60. Mita R, Beaulieu MJ, Field C, Godbout R. Brain fatty acid-binding protein and omega-3/omega-6 fatty acids: mechanistic insight into malignant glioma cell migration. J Biol Chem. (2010) 285:37005-15. doi: 10.1074/jbc.M110.170076

61. Farago N, Feher LZ, Kitajka K, Das UN, Puskas LG. MicroRNA profile of polyunsaturated fatty acid treated glioma cells reveal apoptosis-specific expression changes. Lipids Health Dis. (2011) 10:173. doi: 10.1186/1476-511X-10-173

62. Dadfarma A, Shayanfar M, Benisi-Kohansal S, Mohammad-Shirazi M, Sharifi G, Hosseini $S$, et al. Dietary polyunsaturated fat intake in relation to glioma: a case-control study. Nutr Cancer. (2018) 70:102633. doi: $10.1080 / 01635581.2018 .1494845$ 
63. Bowers LW, Rossi EL, O'Flanagan CH, DeGraffenried LA, Hursting SD. The role of the Insulin/IGF system in cancer: lessons learned from clinical trials and the energy Balance-Cancer link. Front Endocrinol (Lausanne). (2015) 6:77. doi: 10.3389/fendo.2015.00077

64. Masters RC, Liese AD, Haffner SM, Wagenknecht LE, Hanley AJ. Whole and refined grain intakes are related to inflammatory protein concentrations in human plasma. J Nutr. (2010) 140:587-94. doi: 10.3945/jn.109.116640

65. Federico A, Morgillo F, Tuccillo C, Ciardiello F, Loguercio C. Chronic inflammation and oxidative stress in human carcinogenesis. Int $J$ Cancer. (2007) 121:2381-6. doi: 10.1002/ijc.23192

66. Zhou J, Zhang F, Chen J, Zhang S, Wang H. Chlorogenic acid inhibits human glioma u373 cell progression via regulating the SRC/MAPKs signal pathway: based on network pharmacology analysis. Drug Des Devel Ther. (2021) 15:1369-83. doi: 10.2147/DDDT.S2 96862

67. Ku BM, Lee YK, Jeong JY Ryu J, Choi J, Kim JS, et al. Caffeine inhibits cell proliferation and regulates PKA/GSK3beta pathways in U87MG human glioma cells. Mol Cells. (2011) 31:275-9. doi: 10.1007/s10059-011-0 027-5

68. Smrke S, Opitz SE, Vovk I, Yeretzian C. How does roasting affect the antioxidants of a coffee brew? Exploring the antioxidant capacity of coffee via on-line antioxidant assays coupled with size exclusion chromatography. Food Funct. (2013) 4:1082-92. doi: 10.1039/c3fo30377b
69. Mousavi SM, Shayanfar M, Rigi S, Mohammad-Shirazi M, Sharifi G, Esmaillzadeh A. Adherence to the Mediterranean dietary pattern in relation to glioma: a case-control study. Clin Nutr. (2021) 40:3139. doi: 10.1016/j.clnu.2020.05.022

Conflict of Interest: The authors declare that the research was conducted in the absence of any commercial or financial relationships that could be construed as a potential conflict of interest.

Publisher's Note: All claims expressed in this article are solely those of the authors and do not necessarily represent those of their affiliated organizations, or those of the publisher, the editors and the reviewers. Any product that may be evaluated in this article, or claim that may be made by its manufacturer, is not guaranteed or endorsed by the publisher.

Copyright (C) 2022 Zhang, Jiang, Li, He, Chen and Li. This is an open-access article distributed under the terms of the Creative Commons Attribution License (CC BY).

The use, distribution or reproduction in other forums is permitted, provided the original author(s) and the copyright owner(s) are credited and that the original publication in this journal is cited, in accordance with accepted academic practice. No use, distribution or reproduction is permitted which does not comply with these terms. 